\title{
Relation between pulmonary function tests and ultrasonographic changes of asymptomatic anterior chest wall joints in rheumatoid arthritis patients
}

\author{
Mohammed A. Mortada, Fatma Ibrahim Abdelrahman, Amal Abdul-Sattar and Waleed Mansour * (1)
}

\begin{abstract}
Background: Ultrasonography can detect different changes in anterior chest wall (ACW) joints in patients with rheumatoid arthritis (RA) even before being clinically manifested. Airways, pleura, lung parenchyma, and vascular compartment all may be attacked by RA. This study was aiming at detecting the relation between ultrasonographic changes of asymptomatic ACW joints and pulmonary function tests (PFTs) in patients with RA.
\end{abstract}

Results: US detected subclinical changes of ACW joints in (74.2\%) of RA patients with significant difference between total US changes in RA (74.2\%) and control (21.2\%) ( $p<0.001)$. MSJ ankylosing and erosions were highly associated with limited chest expansion in RA group $(P<0.001)$. Restrictive PFTs were associated with SCJ synovitis $(p<0.05)$, SCJ PD activity $(p<0.05)$, SCJ erosions (0.02), and highly associated with MSJ ankylosing and erosions $(p<0.001)$.

Conclusions: This study demonstrated that ultrasonographic subclinical changes in ACW joints are associated with restrictive pattern by spirometry and limited chest expansion in RA patients.

Trial registration: ClinicalTrials.gov Identifier: NCT05119491. Registered 15 November 2021—retrospectively registered.

Keywords: Anterior chest wall joints, Rheumatoid arthritis, Pulmonary function tests, Spirometry

\section{Background}

Many studies had identified the extra-articular pulmonary manifestation of RA by ranges from 20 to $67 \%$ [1, 2]. Airways ,pleura, lung parenchyma, and vascular compartments all may be affected by this disease [3].

Different types of interstitial lung disease (ILD) occur in RA patients, and the most commonly observed ILD are usual interstitial pneumonia, non-specific interstitial pneumonia, and inflammatory airway disease with organizing pneumonia pattern [4]. It has been estimated that pulmonary complications are responsible for

\footnotetext{
*Correspondence: waleedmansour123@gmail.com
}

Faculty of Medicine, Zagazig University, Zagazig, Egypt
$10-20 \%$ mortality in RA patients which is mostly caused by ILD [5].

Cross-sectional studies among patients with RA with interstitial lung problems or chest wall affection reported a high incidence of abnormal pulmonary function tests [6].

Different changes in anterior chest wall (ACW) joints in patients with rheumatoid arthritis (RA) can be detected by ultrasonography even before being clinically manifested [7].

Up to the best of our knowledge, there are no previous studies about the relationship between ultrasound detected subclinical changes in ACW and the pulmonary functions in RA patients. 


\section{Objectives}

To detect the relation between ultrasonographic changes of asymptomatic ACW joints and spirometry in patients with RA.

\section{Hypothesis}

Arthritis of ACW joints may have a role in some pulmonary functions defects in RA patients.

\section{Patients}

The study included 44 subjects (22 RA and 22 controls) that were selected from outpatient clinics and inpatient wards of chest department and rheumatology department of Faculty of Medicine, Zagazig University Hospitals during the period from 1st January 2019 to 30th December 2020. To be eligible for this study, RA patients had to meet the following criteria: (1) age $>20$ years; (2) fulfilled the 2010 American College of Rheumatology/European League Against Rheumatism [8]. Patients were excluded if they were smokers or had a history of interstitial lung disease or current respiratory complaints such as dyspnea, chronic cough, chest trauma, or chest pain.

The study was approved by the Institutional Review Board at the Faculty of Medicine, Zagazig University Hospitals. It has been carried out in accordance with the code of ethics of the world medical association (Declaration of Helsinki 1964) for studies involving humans. A written informed consent was obtained from each participant.

\section{Methods}

\section{Aim}

To detect the relation between ultrasonographic changes of asymptomatic ACW joints and some pulmonary function tests (PFTs), i.e., spirometry in patients with RA.

\section{Study design and setting}

An observational case control study.

\section{Clinical assessment}

Patients and controls were examined in supine position with elbows placed in contact with the body. The anterior chest wall joints (CWJ) which include the right and left sternoclavicular (SCJ) and manubriosternal (MSJ) joints were evaluated for presence/absence of spontaneous pain, pain evoked by digital pressure, swelling, and redness of skin.

Rheumatoid disease activity was assessed clinically using disease activity score (DAS28 ESR) [9] and functional status assessment by health assessment questionnaire (HAQ) [10].

Chest expansion was measured with a tape measure placed circumferentially around the chest wall at the fourth intercostal space [11].

\section{US assessment}

Ultrasonographic B examination (mode and Doppler power mode) of the 3 joints was performed by an experienced rheumatologist. All patients were examined using B-mode (gray scale) real-time MSUS (F37; Hitachi-Aloka, Japan) interfaced with a $10-18-\mathrm{MHz}$ linear array transducer. For each patient and control subject, US examination included a longitudinal section of the left and right SCJ and the MSJ, followed by a cross-section in case erosion was detected. During the examination, synovitis (hypo echoic intracapsular incompressible area with or without Doppler flow), joint effusion (compressible anechoic intracapsular area, absence of Doppler flow), erosion (disruption of the cortical bone line displayed in 2 perpendicular axes), joint space narrowing (reduction of the joint space), ankylosis (complete loss of joint space), or Doppler signal (power Doppler signal) were investigated.

PD parameters were as follows: pulse repetition frequency (PRF) was adjusted at the lowest permissible value to maximize sensitivity. This setting resulted in PRF from 500 to $750 \mathrm{~Hz}$. Flow was additionally demonstrated in 2 planes and confirmed by pulsed wave Doppler spectrum to exclude artifacts.

Computed tomography (HRCT) was done on the chest to exclude any interstitial lung disease that may affect chest expansion and restrictive spirometry pattern.

\section{Spirometry}

Spirometry was done with a Sensormedics Vmax229 system (Sensormedics, Yorba Linda, CA, USA) and included measurement of the forced expiratory volume in $1 \mathrm{~s}\left(\mathrm{FEV}_{1}\right)$, forced vital capacity (FVC), and the ratio of forced expiratory volume in $1 \mathrm{~s}$ to the forced vital capacity $\left(\mathrm{FEV}_{1} / \mathrm{FVC}\right)$.

\section{Statistical analysis}

Data are presented as mean, standard deviation, percentages, or number of cases. Continuous data were compared by independent Student's $t$ tests and categorical data were compared with Pearson chi square tests. Significance was defined by $P$ values less than 0.05 using a two-tailed test. 
Table 1 The clinical characteristics of the rheumatoid arthritis and control groups

\begin{tabular}{|c|c|c|c|c|}
\hline & RA & Control & $T$ test & $P$ \\
\hline Age (years) mean $\pm S D$ & $45.5 \pm 9.8$ & $43.4 \pm 7.7$ & 0.7 & 0.5 \\
\hline Sex (male) $n(\%)$ & $8(36)$ & $9(40.9)$ & 2.2 & 0.6 \\
\hline $\begin{array}{l}\text { Age of onset (years) (mean } \\
\pm \text { SD) }\end{array}$ & $25.5 \pm 4.6$ & NA & NA & NA \\
\hline Duration (years) (mean $\pm S D$ ) & $8.2 \pm 2.7$ & NA & NA & NA \\
\hline $\begin{array}{l}\text { Chest expansion (mean } \pm \\
\text { SD) }\end{array}$ & $2 \pm 1.6$ & $3 \pm 0.6$ & 0.7 & 0.8 \\
\hline Seropositive RF & $15(68.2 \%)$ & $0(0 \%)$ & 3 & $0.007^{*}$ \\
\hline Anti-ccp2 & $17(68.2 \%)$ & $0(0 \%)$ & 2.2 & $0.02 *$ \\
\hline DAS28-ESR (mean \pm SD) & $4.9 \pm 0.7$ & NA & NA & NA \\
\hline mHAQ (mean \pm SD) & $5 \pm 1.09$ & NA & NA & NA \\
\hline \multicolumn{5}{|l|}{ Medications $n(\%$} \\
\hline Biological DMARDs & $11(50)$ & NA & NA & NA \\
\hline Conventional DMARDs & $5(22.7)$ & & & \\
\hline
\end{tabular}

$R A$ rheumatoid arthritis, $S D$ standard deviation, $n$ number

$R F$ rheumatoid factor, Anti-ccp2 anti-cyclic citrullinated peptide, $m H A Q$ modified health assessment questionnaire, DAS disease activity score, ESR erythrocyte sedimentation rate, DMARDs disease modifying agents for rheumatic diseases, NSAIDs non-steroidal anti-inflammatory drugs, NA not applicable

Table 2 Association between the ultrasonographic changes in SCJ and MSJ in control group and rheumatoid patients

\begin{tabular}{lllll}
\hline & $\begin{array}{l}\text { RA } \\
\boldsymbol{n}(\%)\end{array}$ & $\begin{array}{l}\text { Control } \\
\boldsymbol{n}(\%)\end{array}$ & $\left(X^{2}\right)$ & $P$ value \\
\hline SCJ synovitis & $15(68.2)$ & $2(9.1)$ & 21 & $\mathbf{0 . 0 0 0 *}$ \\
SCJ PD activity & $9(40.9)$ & $1(4.5)$ & 13.9 & $\mathbf{0 . 0 0 1 *}$ \\
SCJ erosion & $13(59.1)$ & $1(4.5)$ & 34.2 & $\mathbf{0 . 0 0 0 * *}$ \\
SCJ osteophyte & $4(18.2)$ & $3(13.6)$ & 0.3 & 0.6 \\
MSJ ankylosing & $8(36.4)$ & $0(00)$ & 20.5 & $\mathbf{0 . 0 0 0 * *}$ \\
MSJ erosion & $4(18.2)$ & $0(00)$ & 4.4 & $\mathbf{0 . 0 3 *}$ \\
MSJ osteophyte & $1(4.5)$ & $1(4.5)$ & 0.4 & 0.5 \\
\hline
\end{tabular}

$R A$ rheumatoid arthritis, $n$ number, $S C J$ sternoclavicular joint, $M S J$ manibrusternal joint, $X^{2}$ chi-square test, $P D$ power Doppler signals

${ }^{*} P$ value $<0.05$ is significant

${ }^{*} P$ value $<0.001$ is highly significant

\section{Results}

The present study recruited 44 individuals (22 RA patients and 22 controls) with both groups had comparable age (45.5 \pm 9.8 and $43.4 \pm 7.7$ in RA and control group respectively) and sex distribution ( 8 and 9 were male in RA and control group respectively). Table 1 shows and clinical parameters in both groups.

US detected subclinical changes of ACW joints in 16 (72.7\%) of RA patient with significant difference between total US changes in RA (72.7\%) and control (27.3\%) $(p<0.001)$. MSJ ankylosing and erosions were highly associated with limited chest expansion in RA group $(P<$ 0.001) (Tables 2, 3, 4 and 5).

A restrictive ventilatory pattern by spirometry was found in 14 RA patients $(63.6 \%)$ with mean of $\mathrm{FVC} \%$ of predicted $(65.5 \pm 5), \mathrm{FEV}_{1} \%$ of predicted $(70.4 \pm 9.1) \%$, $\mathrm{FEV}_{1} / \mathrm{FVC}(107.9 \pm 3.23)$ with significant difference $(p<$ $0.05)$ to control with mean of FVC \% of predicted $(99.53$ $\pm 12.12), \mathrm{FEV}_{1} \%$ of predicted (98.3 \pm 13.09$), \mathrm{FEV}_{1} / \mathrm{FVC}$ $(95.1 \pm 2.4)$. This restrictive spirometry pattern was associated with SCJ synovitis $(p<0.05)$, SCJ PD activity $(p<$ $0.05), \mathrm{SCJ}$ erosions (0.02), and highly associated with MSJ ankylosing and erosions $(p<0.001)$.

All RA patients (100\%) with MS (ankylosing and erosions) and SCJ PD activity by US had limited chest expansion and restrictive pattern by spirometry, which were associated also with limited chest expansion with mean of $(2.3 \pm 0.5)$ with significant difference $(p<0.001)$ to non-restrictive spirometry pattern in RA with mean of $(5.2 \pm 1.4)$.

In RA group, ultrasonographic changes and restrictive pattern by spirometry were found to be higher with smoking, longer disease duration and high DAS28.

\section{Discussion}

The use of some pulmonary function tests (PFTs) especially spirometry findings are widely known to provide objective measures of ventilatory functions in a trial to detect and quantify pulmonary impairment in many cardio-pulmonary diseases; moreover, low $\mathrm{FVC}$ in the presence of a normal or elevated $\mathrm{FEV}_{1} / \mathrm{FVC}$ ratio has traditionally been classified as a restrictive pattern [12].

Impairment of some ventilatory functions which is usually evaluated by PFT as a part of the respiratory assessment of RA patients can be limited to individuals suffering from high disease activity, respiratory symptoms, and positive findings in the clinical respiratory examination [7].

Up to our knowledge, arthritis of ACW joints had not been well investigated as a cause of impairment of some PFTs in RA patients.

In the present study, we recruited well defined RA patients who had no history or current complaints of chest problems to correlate features of $\mathrm{ACW}$ joints as detected by ultrasonography with some spirometry parameters.

Also we recruited a comparable group who were apparently healthy for both joints and chest to serve as a control group.

Ultrasonography detected subclinical changes in ACW joints in 16 (72.7\%) of RA patient with significant difference between total US changes in RA than control (27.3\%). Furthermore, these US detected changes were correlated with clinical and laboratory parameters of 
Table 3 Association of the clinical characteristics with ultrasonographic changes in the ACW joints in rheumatoid arthritis patients

\begin{tabular}{|c|c|c|c|c|}
\hline & $\begin{array}{l}\text { RA with US changes } \\
\text { (16) }\end{array}$ & $\begin{array}{l}\text { RA without US changes } \\
\text { (6) }\end{array}$ & $T$ test & $P$ \\
\hline $\begin{array}{l}\text { Age of onset (years) } \\
\text { mean } \pm S D\end{array}$ & $35.2 \pm 7.3$ & $37.9 \pm 6.7$ & 0.7 & 0.5 \\
\hline $\begin{array}{l}\text { Duration } \\
\text { mean } \pm S D\end{array}$ & $17.5 \pm 5.9$ & $5.1 \pm 1.6$ & 2.2 & $0.02^{*}$ \\
\hline $\begin{array}{l}\text { Disease activity } \\
\text { DAS28 ESR }\end{array}$ & $5.9 \pm 0.6$ & $2.9 \pm 0.2$ & 3 & $0.007^{*}$ \\
\hline \multicolumn{5}{|l|}{ Medications: } \\
\hline Biological DMARDS & $4(25)$ & $2(40)$ & & \\
\hline Conventional DMARDS & $12(75)$ & $4(20)$ & 0.5 & 0.8 \\
\hline NSAIDS & $4(23.5)$ & $2(40)$ & & \\
\hline Steroid & $12(5.9)$ & $4(20)$ & 0.9 & 0.3 \\
\hline
\end{tabular}

$R A$ rheumatoid arthritis, US ultrasonography, SD standard deviation, $n$ number, DAS28 Disease Activity Score-28, DMARDs disease modifying agents for rheumatic diseases, NSAIDs non-steroidal anti-inflammatory drugs

${ }^{*} P$ value $<0.05$ is significant

Table 4 Association of the ultrasonographic changes with restrictive spirometry parameters in rheumatoid arthritis patients

\begin{tabular}{|c|c|c|c|c|}
\hline & $\begin{array}{l}\text { RA with restrictive spirometry } \\
\text { parameters (14) } \\
n(\%)\end{array}$ & $\begin{array}{l}\text { RA with normal spirometry } \\
\text { parameters (8) } \\
n(\%)\end{array}$ & $\begin{array}{l}\text { Test } \\
\left(x^{2}\right)\end{array}$ & $P$ \\
\hline SCJ synovitis & $12(85.7)$ & $3(37.5)$ & 4.4 & $0.03^{*}$ \\
\hline SCJ PD activity & $9(64.3)$ & $0(00)$ & 4.7 & $0.03^{*}$ \\
\hline $\mathrm{SCJ}$ erosion & $10(71.4)$ & $3(37.5)$ & 7.8 & $0.005^{*}$ \\
\hline SCJ osteophyte & $1(7.1)$ & $3(37.5)$ & 3.1 & 0.08 \\
\hline MSJ ankylosing & $8(57.1)$ & $0(00)$ & 22 & $0.000^{*}$ \\
\hline MSJ erosion & $1(7.1)$ & $3(37.5)$ & 0.4 & 0.5 \\
\hline MSJ osteophyte & $0(00)$ & $1(12.5)$ & 1.8 & 0.2 \\
\hline
\end{tabular}

$* P$ value $<0.05$ is significant

*P value $<0.001$ is highly significant

This table shows a highly statistically significant difference between the restrictive pulmonary functions in AS patients and MSJ ankylosing and SCJ synovitis, power Dopppler activities, and erosions

Table 5 Results of spirometry parameters in rheumatoid arthritis patients and control group

\begin{tabular}{|c|c|c|c|c|c|c|c|}
\hline & \multicolumn{4}{|c|}{$\mathrm{RA}(n=22)$} & \multirow{2}{*}{\multicolumn{2}{|c|}{ Control $(n=22)$}} & \multirow[t]{3}{*}{$P$} \\
\hline & \multicolumn{2}{|c|}{$\begin{array}{l}\text { Restrictive } \\
(n=14)(63.6 \%)\end{array}$} & \multicolumn{2}{|c|}{$\begin{array}{l}\text { Non-restrictive } \\
(n=8)(36.4 \%)\end{array}$} & & & \\
\hline & Range & Mean \pm SD & Range & Mean \pm SD & Range & Mean \pm SD & \\
\hline $\mathrm{FEV}_{1} \%$ of predicted & $71-73$ & $70.4 \pm 9.1$ & $91.4-95.9$ & $94.9 \pm 25.1$ & $96.1-99.2$ & $98.3 \pm 13.09$ & $<0.05$ \\
\hline $\mathrm{FEV}_{1} / \mathrm{L}$ & $1.69-1.83$ & $1.75 \pm 0.41$ & $1.91-2.31$ & $2.06 \pm 0.55$ & $2.15-2.68$ & $2.45 \pm 0.64$ & \\
\hline $\mathrm{FEV}_{1} / \mathrm{FVC}$ & $106-113$ & $107.9 \pm 3.23$ & $84.65-92.11$ & $85.18 \pm 7.46$ & $94.1-98.3$ & $95.1 \pm 2.4$ & \\
\hline FVC $\%$ of predicted & $63-68$ & $65.5 \pm 5$ & $85.1-88.3$ & $92.27 \pm 22.69$ & $98.56-99.96$ & $99.53 \pm 12.12$ & \\
\hline FVC/L & $1.66-1.75$ & $1.69 \pm 0.37$ & $2.29-2.31$ & $2.21 \pm 0.63$ & $2.61-2.89$ & $2.72 \pm 0.66$ & \\
\hline
\end{tabular}

FEV forced expiratory volume in $1 \mathrm{~s}$, FVC forced vital capacity, SD standard deviation

rheumatoid disease activity. Moreover, MSJ ankylosing and erosions were highly associated with limited chest expansion in RA group.
This may be in concordance with Rodríguez-Henríquez et al. [7] who found abnormalities by ultrasonography in $43 \%$ of examined sternoclavicular joints in 206 
RA patients. Also, they found a correlation between the presences of US synovitis with a higher Disease Activity Score in 28 joints (DAS28) was found.

Complementary to this, MSJ ankylosing and erosions were highly associated with limited chest expansion in RA group. Taking in account that limited chest expansion was associated with restrictive PFTs, this may shed light on possible role of MSJ affection in limited PFTs in RA patients.

Another essential point, PFTs were found to be restrictive in more than half of recruited RA patients. This again may be in accordance with many previous studies that reported restrictive pattern of PFTs to be the most common among RA patients [2-5].

The current study finds a restrictive spirometry pattern which was associated with SCJ synovitis, SCJ erosions and highly associated with MSJ ankylosing and erosions.

Up to be the best of our knowledge, this is maybe the first study to demonstrate such correlation between subclinical changes of ACW joints and restrictive spirometry pattern in rheumatoid arthritis patients. In turn, this may raise the need to pay more attention to assess the ACW joints in the routine assessment of RA activity and more specific measures to confirm the restrictive ventilatory defect.

The main limitation of this is the small number of cases enrolled. We may recommend further large study to validate our pilot results.

\section{Conclusions}

To conclude these data, we found a direct correlation between US detected abnormalities in ACW joints and the restrictive pattern of spirometry parameters in RA patients who are asymptomatic as regards both chest complains and arthritis of ACW joints.

\section{Abbreviations \\ ACW: Anterior chest wall; RA: Rheumatoid arthritis; MSJ: Manibrusternal joint: SCJ: Sternoclavicular joint; US: Ultrasound; HRCT: High-resolution computed tomography; PFTs: Pulmonary function tests.}

\section{Acknowledgements}

Many thanks for all paramedical personnel at pulmonary function and ultrasonography units at chest, rheumatology, and rehabilitation units of Zagazig University hospitals.

\section{Authors' contributions \\ Conceptualization: WM, MM, and AA. Methodology: WM, MM, and AA. Pulmo- nary function tests: WM. Joint US: MM and AA. Writing, review, and editing: WM and FI. Software and statistics: Fl. Original draft preparation: MM and FI. Approval of final manuscript: all authors.}

\section{Funding}

Not applicable.

\section{Declarations}

\section{Ethics approval and consent to participate}

This has been carried out in accordance with the code of ethics of the world medical association (Declaration of Helsinki 1964) for studies involving humans. A written informed consent was obtained from each participant, with a confirmation of IRB (no,7093), of Faculty of Medicine, Zagazig University.

\section{Consent for publication}

It was taken from all authors.

\section{Competing interests}

The authors declare that they have no competing interests.

Received: 12 August 2021 Accepted: 12 January 2022

Published online: 29 January 2022

References

1. Provenzano G (2002) Asymptomatic pulmonary involvement in RA. Thorax. 57(2):187-188

2. Cojocaru M, Cojocaru IM, Silosi I, Vrabie CD, Tanasescu R (2010) Extra-articular manifestations in rheumatoid arthritis. Maedica (Bucur) 5(4):286-291

3. Dawson JK, Fewins HE, Desmond J, Lynch MP, Graham DR (2001) Fibrosing alveolitis in patients with rheumatoid arthritis as assessed by high resolution computed tomography, chest radiography, and pulmonary function tests. Thorax. 56(8):622-627. https://doi.org/10.1136/thorax.56.8. 622 PMID: 11462065; PMCID: PMC1746113

4. Bongartz T, Nannini C, Medina-Velasquez YF, Achenbach SJ, Crowson CS, Ryu J, Vassallo R, Gabriel SE, Matteson EL (2010) Incidence and mortality of interstitial lung disease in rheumatoid arthritis: a population-based study. Arthritis Rheum 62:1583-1591

5. Avnon LS, Manzur F, Bolotin A, Heimer D, Flusser D, Buskila D, Sukenik S, Abu-Shakra M (2009) Pulmonary functions testing in patients with rheumatoid arthritis. Isr Med Assoc J 11(2):83-87 PMID: 19432035

6. Rodríguez-Henríquez P, Solano C, Peña A, León-Hernández S, HernándezDíaz C, Gutiérrez M, Pineda C (2013) Sternoclavicular joint involvement in rheumatoid arthritis: clinical and ultrasound findings of a neglected joint Arthritis Care Res 65(7):1177-1182. https://doi.org/10.1002/acr.21958 PMID: 23335586

7. Aletaha D, Neogi T, Silman AJ, Funovits J, Felson DT, Bingham CO 3rd, Birnbaum NS, Burmester GR, Bykerk VP, Cohen MD, Combe B, Costenbader KH, Dougados M, Emery P, Ferraccioli G, Hazes JM, Hobbs K, Huizinga TW, Kavanaugh A, Kay J, Kvien TK, Laing T, Mease P, Ménard HA, Moreland LW, Naden RL, Pincus T, Smolen JS, Stanislawska-Biernat E, Symmons D, Tak PP, Upchurch KS, Vencovský J, Wolfe F, Hawker G (2010) 2010 rheumatoid arthritis classification criteria: an American College of Rheumatology/European league against rheumatism collaborative initiative. Arthritis Rheum 62(9):2569-2581. https://doi.org/10.1002/art.27584 PMID: 20872595

8. van der Heijde DM, van't Hof MA, van Riel PL, Theunisse LA, Lubberts EW, van Leeuwen MA, van Rijswijk MH, van de Putte LB (1990) Judging disease activity in clinical practice in rheumatoid arthritis: first step in the development of a disease activity score. Ann Rheum Dis 49(11):916920. https://doi.org/10.1136/ard.49.11.916 PMID: 2256738; PMCID: PMC 1004262

9. Bruce B, Fries JF (2005) The health assessment questionnaire (HAQ). Clin Exp Rheumatol 23(5 Suppl 39):S14-S18 PMID: 16273780

10. Illeez Memetoğlu Ö, Bütün B, Sezer I (2016) Chest expansion and modified schober measurement values in a healthy, adult population. Arch Rheumatol 31(2):145-150Published 2016 Jan 27. https://doi.org/10.5606/ ArchRheumatol.2016.5765

11. Ranu H, Wilde M, Madden B (2011) Pulmonary function tests. Ulster Med J 80(2):84-90

\section{Publisher's Note}

Springer Nature remains neutral with regard to jurisdictional claims in published maps and institutional affiliations. 